Ann. Biol. anim. Bioch. Biophys., 1977, 17 (3 A), 325-329.

\title{
Resumption of menstruation and fertility after cesarian in Macaca fascicularis.
}

par D.-C. DANG

Laboratoire d'Anatomie, UER Biomédicale, 45, rue des Saints-Pères, 75006 Paris, France

Laboratoire de Physiologie de la Reproduction, Université Paris VI, 78350 jouy-en-Josas, France

Summary. Cesarian is performed on 30 Macaca fascicularis females between day 37 and 78 of pregnancy. After cesarian, menstruation reappears within 22-53 days whatever the time of year (see fig. 1). Cycles become regular immediately after resumption of menstruation irrespective of the time elapsed before return $(r=0.32)$ or age of fetus (see fig. 2$)$. Ovulation occurs before resumption of menstruation and females are immediately fertile (see table).

These results closely duplicate those found in woman after abortion.

\section{Introduction.}

The postpartum in mammals is characterized by a more or less long period of ovarian inactivity, which is longer if the female suckles (Thibault and Levasseur, 1974). Within one month after birth without suckling, the ewe returns to estrus with ovulation (Mauleon and Dauzier, 1965) ; in the cow this period lasts 1 to 3 months and in the sow 2 weeks (Hafez and Jainudeen, 1974). In woman after abortion or birth without lactation, menstruation resumes within 20 to 50 days (Vorherr, 1973).

In this report we study the time elapsed before resumption of ovarian activity and fertility in the crab-eating macaque, Macaca fascicularis, using cesarian to interrupt pregnancy at different stages.

\section{Material and methods.}

Thirty females imported from southeast Asia were used in this study. The conditions in which they are raised have been described (Dang, 1977). Cesarian was done aseptically between day 37 and 78 of pregnancy by median incision of the uterus. The initial anesthesia (Keiamine, Parkes-Davis Laboratory), given by intramuscular injection at a dose of $10 \mathrm{mg} / \mathrm{kg}$, was maintained with Pentothal administered by intravenous pathway (about $0.1 \mathrm{~g} /$ animal). 
The study consisted of 2 experiments. In the first, the females were not put with the males before resumption of menstruation ; the second group was mated between day 13 and 22, counting from the day of cesarian. From day 22 after cesarian, the animals were examined for menstruation 6 days per week by vaginal smear with a cotton swab.

In order to exactly defermine the time of fertilization, females were put with the males for 24-48 hours from day 12 to day 14 of the cycle, counting from the first day of menstruation. New pregnancies were determined by uterine palpation through the rectum at day 28 postcoitum and by the presence of characteristic post-implantation menstruation. Several births confirmed the accuracy of the diagnosis.

\section{Results and discussion.}

Resumption of menstruation.

In the first experiment, menstruation reappeared rapidly no matter in what season cesarian was done, i.e. in a time lapse of 22 to 53 days (mean $=38.0 \pm 2.6$ days). Statistical analysis shows that the period between the day of cesarian and day the menstruation resumes is slightly longer than the menstrual cycle of this primate which is $34.5 \pm 1.3$ days (Dang, 1977).

In the second experiment where females were mated from day 13 to 22 after the day of cesarian, the mean time lapse before resumption of menstruation in nonpregnant females $(45.2 \pm 2.8$ days) is longer than in the first experiment where subjects were not mated (see fig. 1). This difference may be because there would have been shorter time lapse in fertilized females (31-39 days), if they had not been mated.

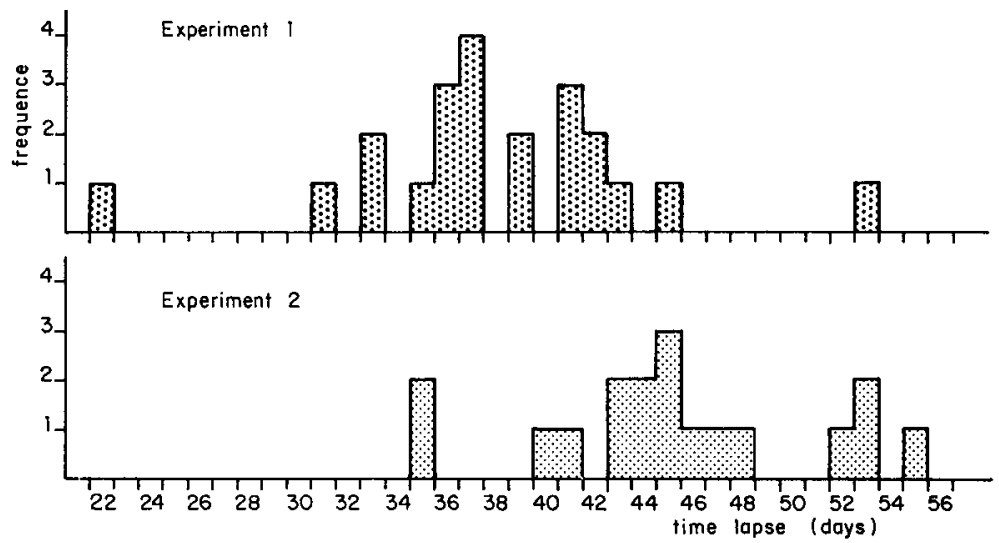

FIG. 1. - Histograms showing fime lapse between cesarian and resumption of menstruation.

The length of this mensiruation (3-6 days) corresponds to that of the normal cycle (Dang, 1974).

Thirteen females underwent 2 or 3 successive cesarians at different times during 
pregnancy and time elapsed before resumption of menstruation was the same. There is no correlation $(r=0.16)$ between age of fetus taken and time lapse before return to menstruation during the period under consideration (37-78 days) (see fig. 2 ).

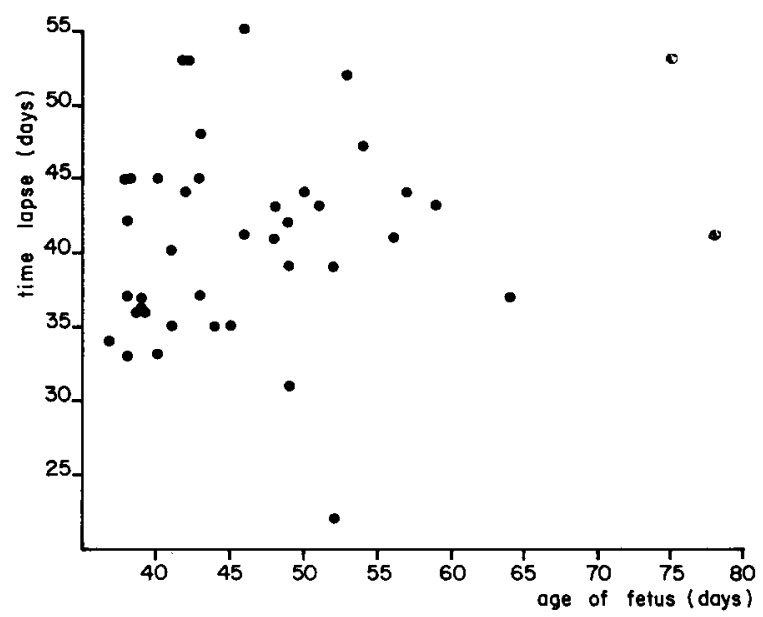

FIG. 2. - Absence of correlation between age of fetus taken and time elapsed before menstruation resumes.

When mating was not followed by new pregnancy, the length of the two following cycles ( $32.6 \pm 2.8$ days; $35.5 \pm 4.8$ days) was the same as in the normal cycle. Moreover, the time elapsed before return to menstruation does not affect the length of the cycle coming after $(r=0,32)$.

\section{Post-cesarian fertility.}

The table opposite shows that the female is fertile immediately after cesarian before menstruation reappears, at least when operated on at day 37 to 47 of pregnancy.

\section{Pregnancy.}

In these females, post-implantation menstruation appears after $19.1 \pm 3.6$ days, counting from the 18 th day of mating. This period is similar to that seen in the same females after fertilization during the normal cycle (18.5 44.3 days ; see table).

The ovulation in these females thus seems to occur 18 to 22 days after cesarian. This first follicular phase after cesarian is thus 5-8 days longer than that of the normal menstrual cycle. This confirms the time lapse between the cesarian and first menstruation (38.0 \pm 2.6 as against $34.5 \pm 1.3$ days).

Conception rate in females fertilized before resumption of menstruation (8/26) is at least equal to that obtained during the two following menstrual cycles $(6 / 30$ and $4 / 20$, respectively) during which females are mated only at days 13 and 14 of the cycle. 
TABLE

Fertility after cesarian

\begin{tabular}{|c|c|c|c|c|}
\hline \multirow{2}{*}{$\begin{array}{l}\text { Age of fetus } \\
\text { (days) }\end{array}$} & \multirow{2}{*}{$\begin{array}{l}\text { Days of mating } \\
\text { after cesarian }\end{array}$} & \multirow[b]{2}{*}{ Pregnancy } & \multicolumn{2}{|c|}{$\begin{array}{l}\text { Time elapsed before } \\
\text { post implantation } \\
\text { menstruations (days) }\end{array}$} \\
\hline & & & $\begin{array}{c}\text { after } \\
\text { cesarian }\end{array}$ & $\begin{array}{c}\text { during } \\
\text { normal cycle } \\
\text { (mating at } \\
\text { day 13-14) }\end{array}$ \\
\hline 37 & $14-20$ & yes & 18 & 17 \\
\hline 38 & $13-18$ & no & - & - \\
\hline 38 & $14-20$ & yes & 21 & 19 \\
\hline 38 & $14-20$ & no & $=$ & - \\
\hline 39 & $14-20$ & yes & 13 & 15 \\
\hline 40 & $14-22$ & yes & 19 & - \\
\hline 41 & $14-19$ & no & - & - \\
\hline 41 & $14-21$ & no & - & - \\
\hline 42 & $14-21$ & no & - & - \\
\hline 42 & $14-21$ & no & - & - \\
\hline 42 & $14-21$ & no & - & - \\
\hline 43 & $14-20$ & no & - & - \\
\hline 43 & $14-21$ & no & - & - \\
\hline 44 & $14-21$ & yes & 25 & 26 \\
\hline 45 & $13-22$ & yes & 15 & 15 \\
\hline 45 & $15-16$ & no & - & - \\
\hline 46 & $14-21$ & no & - & - \\
\hline 47 & $13-18$ & yes & 17 & - \\
\hline 47 & $17-20$ & yes & 25 & 19 \\
\hline 48 & $14-20$ & no & - & - \\
\hline 50 & $14-20$ & no & - & - \\
\hline 51 & $14-20$ & no & - & - \\
\hline 53 & $18-19$ & no & - & - \\
\hline 54 & $14-21$ & no & - & - \\
\hline 57 & $14-20$ & no & - & - \\
\hline \multirow[t]{2}{*}{78} & $14-20$ & no & - & - \\
\hline & & $8 / 26$ & $19,1 \pm 3,6$ & $18,5+4,3$ \\
\hline
\end{tabular}

In woman, the resumption of menstruation after abortion or birth, when there is no lactation, occurs whithin 20 to 50 days, and the length of the menstrual cycle after return is already normal. In about 60 p. 100 of cases, ovulation precedes resumption of menstruation (Vorherr, 1973). This is also true in the macaque.

Accepté en novembre 1976.

Acknowledgments. - The author wishes to thank C. Thibault for his helpful criticism and Mrs. Alice Daifuku who translated the text into English. He is also indebted to $\mathrm{Mr}$. G. Apheceix for his technical assistance which is greatly appreciated. He is grateful to the Caisse Nationale de l'Assurance Maladie des Travailleurs Salariés (Contract 71-72-73) and to the C.N.R.S. which helped to make this study possible. 


\section{References}

DANG D. C., 1974. Maîtrise du cycle menstruel par la progestérone el fertilité chez Mocaca fascicularis. J. Gyn. Obst. Biol. Reprod., 3, 469-476.

DANG D. C., 1977. Absence of seasonal variation in the length of the menstrual cycle and the fertility of the Crab-eating Macaque (Macaca fascicularis) raised under natural daylight ratio. Ann. Biol. anim. Bioch. Biophys., 17, 1-7.

HAFEZ E.S.E., JAINUDEEN M. R., 1974. Gestation, prenatal physiology and parturition, 166-202. In E.S.E. HAFEZ, Reproduction in farm animals, Lea and Febiger, Philadelphia.

MAULEON P., DAUZIER L., 1965. Variations de la durée de l'anoestrus de lactation chez les brebis Ile-de-France. Ann. Biol. anim. Bioch. Biophys., 5, 131-143.

VORHERR H., 1973. Contraception after abortion and post-partum. Am. J. Obstet. Gynecol., 117, $1002-1024$.

THIBAULT C., LEVASSEUR M. C., 1974. Reproductive life cycle, 82-100. In E.S.E. HAFEZ, Reproduction in farm animals, Lea and Febiger, Philadelphia. 